\title{
Características dos peritos contadores judiciais do estado de Pernambuco
}

\author{
Vitória Regina Alves de Souza ${ }^{7}$ \\ Josaias Santana dos Santos ${ }^{2}$ \\ Florisvaldo Cunha Cavalcante Junior ${ }^{3}$
}

\begin{abstract}
Resumo: A perícia contábil é um ramo da contabilidade que visa elaborar uma prova pericial ou laudo pericial. Trata-se de uma forma de garantir a veracidade das informações apresentadas pelas partes envolvidas em um processo judicial. Assim, a problemática deste artigo é investigar quais as particularidades da profissão de peritos contadores e o objetivo geral é caracterizar o perfil dos peritos contadores nas esferas judiciais do estado de Pernambuco. Realizou-se a coleta de dados por meio de questionário misto aplicado entre os peritos constantes no Cadastro Nacional de Peritos Contadores (CNPC) até 31 de dezembro de 2017. Os questionários foram enviados por e-mail para todos os cadastrados e foram obtidas 25 respostas, o que representa 18,65\% do universo. A análise dos dados classifica-se como quantitativa e o método utilizado foi o Survey. Não obstante a área civil proporcionar uma remuneração maior, a atividade que apresentou maior demanda foi a área trabalhista. A obtenção de documentos necessários para a realização de perícia é a principal dificuldade citada pelos peritos. Constatou-se que as principais dificuldades dos peritos para se inserir no mercado de trabalho são: a obtenção de documentos necessários para a realização do processo, baixa remuneração, tempo para realização da perícia, nomeação por partes de juízes e apoio das partes envolvidas. De modo geral, os referidos profissionais estão satisfeitos com a profissão e participam de cursos de educação continuada duas vezes a cada seis meses.
\end{abstract}

Palavras-chave: Contabilidade. Perito contador. Perícia contábil.

Abstract: Accounting expertise is a branch of accounting that aims to draw up an expert evidence or expert report. A way of proving through facts litigated the veracity of the information presented by the parties involved in a lawsuit. Thus, the problem is to investigate what are the particularities of the profession of accountant experts and the general objective is to characterize the profile of accountant experts in the judicial spheres of the State of Pernambuco. Data collection was performed through the mixed questionnaire, limited to apply the questionnaire only to experts in the National Register of Accountants (CNPC), until December 31, 2017. The questionnaires were sent by email, for $100 \%$ of the registered experts and 25 answers were obtained, representing $18.65 \%$ of the universe. Data analysis is classified as quantitative and the method used was Survey. The activity with the highest demand is the labor area, however it is the civil area that provides the highest compensation. Obtaining the necessary documents to perform the expertise is the main difficulty cited by the experts. It was found that the main difficulties encountered by experts in entering the labor market are obtaining the necessary documents to carry out the process, low remuneration, time to perform the expertise, appointment by judges and support from the parties involved. In addition, they are satisfied with the profession and attend continuing education courses twice every six months.

Keywords: Accounting. Accountant expert. Accounting expertise.

\footnotetext{
${ }^{1}$ Graduação em Ciências Contábeis pela Faculdade de Ciências Sociais e Aplicadas de Petrolina (FACAPE). E-mail: vitoria.souza@yahoo.com.br.

${ }^{2}$ Graduação em Ciências Contábeis pela Faculdade de Ciências Sociais e Aplicadas de Petrolina (FACAPE). Mestre em Ciências Contábeis pela FUCAPE. Professor Universitário da FACAPE. E-mail: josaias@yahoo.com.br.

${ }^{3}$ Graduação em Ciências Contábeis pela Faculdade de Ciências Sociais e Aplicadas de Petrolina (FACAPE). Mestre em Controladoria pela UFRPE. Professor do IFSERTÃO-PE. E-mail: junior.cavalcantte@yahoo.com.br.
} 


\section{Introdução}

A perícia contábil é um ramo da contabilidade que visa elaborar uma prova pericial ou laudo pericial. Uma forma de comprovar por meio de fatos colocados em litígios a veracidade das informações apresentadas pelas partes envolvidas em um processo judicial. A profissão do perito contábil é de competência exclusiva do contador devidamente registrado no Conselho Regional de Contabilidade (CRC).

Atualmente, o número de processos que demanda perícia contábil apresenta-se crescente. Desse modo, a "função do contador possui abrangência maior, uma vez que há necessidade de oferecer informações ao judiciário para a solução de litígios" (SANTOS et al., 2013, p. 55).

Para Caríssimo et al. (2016, p. 47), "a perícia contábil, cumprindo os objetivos da contabilidade, também gera informação útil para a tomada de decisão, sendo ainda instrumento de prova, evidenciação e verificação da veracidade dos fatos".

Com relação às exigências do perfil do perito contábil, Bizotto, Motta e Ramoni (2015) relatam que a graduação não garante o sucesso profissional, muito pelo contrário, é o início de uma longa caminhada, cuja premissa é a educação continuada, por isso, é responsabilidade do perito estar atualizado, focado nos acontecimentos atuais. Ou seja, a graduação não é suficiente para a inserção no mercado de trabalho, é importante estar inscrito no Programa de Educação Continuada ofertado pelo CRC e modernizar-se no que diz respeito à legislação vigente.

De acordo com definição da NBC T 13, aprovada pela Resolução CFC no 731, Perícia Contábil é “o conjunto de procedimentos técnico-científicos destinados a levar à instância decisória elementos de provas necessários a subsidiar a justa solução do litígio ou constatação de fato, mediante laudo pericial contábil e/ou parecer técnico-contábil”.

Quando há divergências entre as partes em um processo judicial, condição que requer um conhecimento técnico na área contábil, o juiz convoca um perito-contador. Esse profissional é responsável por apresentar uma prova (laudo) com o propósito de solucionar o problema das partes envolvidas.

Segundo Bizotto, Motta e Ramoni (2015), as partes envolvidas, sejam jurídicas, sejam físicas, buscam a opinião de um especialista, por isso o perito contábil deve atuar de maneira íntegra e manter-se acima de qualquer suspeita, uma vez que sua credibilidade se relaciona com o resultado do seu trabalho. Assim, o problema que norteia esta pesquisa é: quais as particularidades da profissão dos peritos contadores? Nesse contexto, o objetivo geral é caracterizar o perfil dos peritos contadores na esfera judicial do Estado de Pernambuco.

Em suma, este estudo é relevante porque pretende relacionar nível de conhecimento, atuação e educação continuada dos peritos contadores, em um cenário no qual as exigências por profissional qualificado, com habilidades e competências diferenciadas vêm crescendo nos últimos anos. Ademais, tanto no âmbito 
nacional quanto internacional, existe uma escassez de pesquisas que envolvem o ramo de perícia e a contabilidade, particularmente a perícia contábil (MURRO; BUEREN, 2016).

É fundamental compreender o perfil de um perito contador com a finalidade de contribuir com as informações para os discentes de ciências contábeis que almejam essa profissão, uma oportunidade de ingressar no mercado de trabalho.

\section{Referencial teórico}

Pericia contábil

A perícia contábil é uma técnica utilizada para solucionar questões em litígios por meio de um laudo pericial ou prova pericial, considerando as normas profissionais e jurídicas, bem como a legislação pertinente à temática apresentada pelas partes envolvidas no processo judicial. Conforme Araújo e Lima (2008), “a perícia contábil constitui um importante instrumento à consecução do objetivo do Direito, ao aclarar situações e controvérsias que necessitam de conhecimentos técnicos e científicos aplicáveis à matéria do litígio".

O conceito perícia contábil está “necessariamente ligado ao conceito geral de perícia, visto que a adjetivação apenas designa a matéria sobre a qual a perícia recairá, ou em qual área do conhecimento humano irá atuar” (MONTANDON, M. M.; SIQUEIRA, J. R. M.; OHAYON, 2013, p. 7).

Segundo Andrade e Travassos (2009), a perícia está arraigada no contexto das provas aceitas no direito brasileiro, ocorre devido à necessidade de conhecimento técnico-científico sobre determinada questão posta em juízo.

Dessa forma, a perícia contábil objetiva-se na constatação, nas demonstrações ou prova da verdade sobre determinado assunto. Por meio do laudo pericial, realiza-se o processo de transferência de conhecimento para o ordenamento da instância decisória extrajudicial ou judicial.

Em relação às exigências para exercer a profissão, a NBC PP01 - Perícia Contábil, aprovada pela Resolução CFC no 1.243, apresenta os seguintes requisitos: “o contador regularmente registrado em conselho Regional de Contabilidade, que exerce a atividade pericial de forma pessoal, devendo ser profundo conhecedor, por suas qualidades e experiências, da matéria periciada.”

De acordo com Andrade e Travassos (2009), as perícias são classificadas segundo os ambientes de atuação, e dessa forma se dividem em: perícia judicial, semijudicial, extrajudicial e perícia arbitral. As descrições correspondentes a cada tipologia pericial estão apresentadas no Quadro 1: 


\section{Quadro 1 - Tipos de perícias}

\begin{tabular}{|l|l|}
\hline Tipos de perícia & Descrição \\
\hline Judicial & $\begin{array}{l}\text { Realizada nos procedimentos do Poder Judiciário. Ao deferir a perícia, o } \\
\text { juiz nomeia o perito e as partes devem indicar os assistentes, obedecendo } \\
\text { aos prazos estabelecidos, momento em que também deverão apresentar os } \\
\text { quesitos a que os peritos devem responder. }\end{array}$ \\
\hline Semijudicial & $\begin{array}{l}\text { Realizada dentro do aparato institucional do Estado sem a utilização do } \\
\text { Poder Judiciário. Tem por finalidade apurar atos ou fatos praticados por } \\
\text { funcionários públicos como, por exemplo, corrupção, peculato etc. }\end{array}$ \\
\hline Extrajudicial & $\begin{array}{l}\text { Realizada fora da esfera judicial, independentemente de tramitação judicial. } \\
\text { Porém, pode se transformar em uma perícia judicial quando houver um } \\
\text { processo (MACHADO et al., 2007, TRAVASSO et al., 2009). Os principais } \\
\text { casos que se aplicam a esse tipo de perícia são "Fusão, Cisão, Incorporação, } \\
\text { Medidas administrativas, Reavaliação de ativo permanente e patrimônio } \\
\text { líquido" (MACHADO et al., 2007, apud TRAVASSO et al., 2009). }\end{array}$ \\
\hline Arbitral & $\begin{array}{l}\text { Realizada no juízo arbitral - instância decisória criada pela vontade das } \\
\text { partes - por destinar-se a funcionar como meio de prova no juízo arbitral. } \\
\text { Essa espécie de perícia é considerada como se judicial fosse. }\end{array}$ \\
\hline
\end{tabular}

Fonte: Adaptado de Andrade e Travassos (2009).

No que se refere aos campos de atuação do perito contábil, Matias e Silva (2011) relatam que ainda é possível perceber um pouco de insegurança dos profissionais em relação ao campo de atuação e às atividades básicas vinculadas às perícias contábeis.

Portanto, "a perícia contábil compõe-se de inúmeros fatores que precisam ser considerados para que seja executada de forma apropriada" (NEVES JÚNIOR, et al., 2013, p. 301).

\section{Perfil profissional}

O profissional em perícia contábil é, antes de tudo, um profissional contábil, pois apenas este poderá exercer a função de perito em processos judiciais, extrajudiciais e arbitral. Desse modo, o Ministério do Trabalho define, na Classificação Brasileira de Ocupações (CBO), as competências pessoais necessárias aos que lidam com a atividade contábil, incluindo o perito contador: agir eticamente, agir de forma educada, demonstrar objetividade, ter conhecimentos básicos de informática, raciocínio logico, discrição, manter-se atencioso, demonstrar flexibilidade, zelar pelas informações, manter-se atualizado 
profissionalmente e atualizado perante a legislação, falar corretamente, guardar sigilo, trabalhar em equipe, demonstrar conhecimento de outras línguas, manter-se informado e agir com dinamismo.

Além dos atributos descritos anteriormente, o perito contábil possui uma função pericial revestida de aspectos e requisitos legais, técnicos, psicológicos, sociais e profissionais. Segundo o estudo de Gonçalves et al. (2014), são cinco as características consideradas mais importantes de forma geral em todos os grupos: visão analítica, senso criterioso, capacidade para trabalhar pressionado, postura ética e perfil de investigador.

Todas essas técnicas e qualificativos, conforme explanam Santos et al. (2013), tornam o perito contador capaz de desenvolver a perícia. No entanto, para consolidar-se no mercado, é necessário exercer a função com eficácia e assumir determinadas atitudes na execução dos trabalhos, como comprometer-se com a ética, empenhar-se nas atividades e atuar com independência, por exemplo. Caso o perito contador adote uma prática considerada incorreta que, notadamente, possa trazer danos às partes envolvidas, responderá pelos seus atos e estará sujeito a punições do Conselho Regional de Contabilidade (CRC) de sua jurisdição, bem como às sanções previstas no Código Penal.

Na pesquisa realizada por Bizzoto, Motta e Ramoni (2015), 44\% dos entrevistados possuem no seu currículo apenas a graduação. Nos achados de Feldeman e Gauer (2010), esse percentual sobe para 73\%. Tais informações demonstram que grande parte dos peritos não possui especialização para exercer a profissão de perito contador.

Vale ressaltar que, conforme os dados coletados por Feldeman e Gauer (2010), a área judicial civil manifesta maior demanda por perícias contábeis. Diferentemente, Bizzoto, Motta e Ramoni (2015) afirmaram que a justiça do trabalho apresentou maior demanda.

Os peritos contadores encontram muitas dificuldades para atuar no mercado de trabalho. Nos estudos de Bizzoto, Motta e Ramoni (2015) a principal dificuldade é a nomeação por parte dos juízes. Feldeman e Gauer (2010) apontam a fixação de honorários como a maior barreira.

Legislação aplicada à atividade do perito contador

De acordo com a NBC PP 01- Perito Contábil, aprovada pela Resolução CFC nº 1.243, para exercer a profissão de perito contador, é preciso ser registrado no CRC. Nos processos em que é necessário um conhecimento técnico ou científico, o juiz será auxiliado por um perito habilitado (art. 156, §1, $\mathrm{CPC}$ ).

A lei $\mathrm{n}^{\circ} 13.105 / 2015$ possibilita às partes envolvidas no processo selecionarem seus peritos assistentes para atuar no caso (art. 471, CPC). No entanto, de acordo com a Resolução do CFC nº 1.243/2009, 
existem alguns impedimentos e suspeição que não permitem ao perito atuar em determinado processo. Essas condições estão relacionadas nos itens abaixo:

(a) ser amigo íntimo de qualquer das partes;

(b) ser inimigo capital de qualquer das partes;

(c) ser devedor ou credor em mora de qualquer das partes, dos seus cônjuges, de parentes destes em linha reta ou em linha colateral até o terceiro grau ou entidades das quais esses façam parte de seu quadro societário ou de direção;

(d) ser herdeiro presuntivo ou donatário de alguma das partes ou dos seus cônjuges;

(e) ser parceiro, empregador ou empregado de alguma das partes;

(f) aconselhar, de alguma forma, parte envolvida no litígio acerca do objeto da discussão; e

(g) houver qualquer interesse no julgamento da causa em favor de alguma das partes (CFC, 2015).

Os impedimentos ou suspeição são circunstâncias que impossibilitam os peritos contadores de executarem suas tarefas no âmbito judicial, extrajudicial ou arbitral. Quando não se tem nenhuma vedação para exercer as funções, o perito contador deve atuar com zelo profissional e possuir os seguintes requisitos:

(a) cumprir os prazos fixados pelo juiz em perícia judicial e nos termos contratados em perícia extrajudicial, inclusive arbitral;

(b) assumir a responsabilidade pessoal por todas as informações prestadas, quesitos respondidos, procedimentos adotados, diligências realizadas, valores apurados e conclusões apresentadas no laudo pericial contábil e no parecer técnico-contábil;

(c) prestar os esclarecimentos determinados pela autoridade competente, respeitados os prazos legais ou contratuais;

(d) propugnar pela celeridade processual, valendo-se dos meios que garantam eficiência, segurança, publicidade dos atos periciais, economicidade, o contraditório e a ampla defesa;

(e) ser prudente, no limite dos aspectos técnico-científicos, e atento às consequências advindas dos seus atos;

(f) ser receptivo aos argumentos e críticas, podendo ratificar ou retificar o posicionamento anterior (CFC, 2015).

O zelo profissional, conforme a NBC PG 100 - Aplicação Geral aos profissionais da contabilidade, aprovada pela resolução $\mathrm{n}^{\circ} 12.249 / 10$, quer dizer que o profissional deve manter um nível adequado de conhecimento e habilidades na execução das funções, para que seja reconhecido como um profissional, cujas características são adequadas e necessárias para as atividades ordenadas. E atuar sempre com embasamento nas normas técnicas e profissionais aplicáveis a sua profissão.

Com o conhecimento técnico na área para a qual foi nomeado, o perito deve apresentar um laudo pericial com o objetivo de solucionar os conflitos existentes entre as partes envolvidas no processo judicial. O laudo deverá conter uma linguagem menos técnica, discriminar de que maneira alcançou os resultados e apoiar-se em uma fundamentação (art.473, \ $1^{\circ}, \mathrm{CPC}$ ). 
Metodologia

O presente estudo tem o objetivo de caracterizar o perfil dos peritos contadores judiciais do estado de Pernambuco. Para tanto, definiu-se uma amostra de profissionais realizou-se uma pesquisa descritiva com o propósito de identificar seus traços e percepções.

A coleta de dados foi realizada por meio do questionário misto com a finalidade de filtrar informações e dados que serviram de base para a investigação proposta. Cervo e Bervian (2002) apontam diversos parâmetros que caracterizam as vantagens de utilização do questionário. Afirmam também que essa é a forma mais usada para coletar dados, pois possibilita medir com melhor exatidão o que se deseja.

O estudo foi aplicado somente entre os peritos que constavam no cadastro do Conselho Nacional de Peritos Contadores (CNPC) até 31 de dezembro de 2017. Esse cadastro tem o objetivo de oferecer ao judiciário e à sociedade uma lista de profissionais qualificados que atuam como peritos contábeis. Ademais, permite ao Sistema CFC/CRC identificá-los com o intuito de dar maior celeridade à ação do poder judiciário, uma vez que se poderá conhecer geograficamente e, também, por especialidade, a disponibilidade desses profissionais.

Segundo o CNPC (2017), até dezembro de 2017, havia 134 peritos inscritos atuando no estado de Pernambuco. Os questionários foram enviados por e-mail, para todos os peritos cadastrados e obteve-se um total de 25 respostas, o que representa 18,65\% do universo. Os dados receberam um tratamento quantitativo e o método utilizado foi o Survey. A análise dos dados coletados pelo questionário pautou-se na estatística simples e descritiva.

\section{Análise e discussão dos resultados}

O questionário foi encaminhado para peritos contadores de Pernambuco cadastrados no Cadastro Nacional de Peritos Contadores (CNPC). Obteve-se um total de 25 respostas. A primeira parte do questionário visa observar o perfil dos entrevistados; a segunda trata da parte específica da pesquisa.

A primeira indagação teve o intuito de verificar o gênero dos peritos contadores do estado de Pernambuco: 
Gráfico 1 - Gênero dos peritos contadores de Pernambuco

\section{MASCULINO -FEMININO}

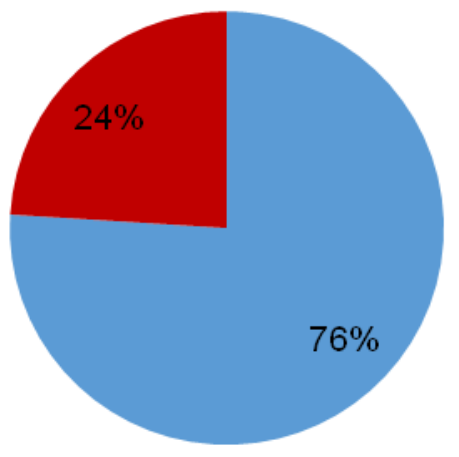

Fonte: Dados da pesquisa.

O Gráfico 1 mostra que há mais representatividade do gênero masculino, em que 19 dos entrevistados são homens (cerca de 76\%) e 6 são mulheres (cerca de 24\%).

Ainda referente ao perfil dos entrevistados, procurou-se observar a faixa etária dos entrevistados. Essas informações foram sintetizadas no Gráfico 2:

\section{Gráfico 2 - Faixa etária}

- 21 a 30 anos $\quad 31$ a 40 anos $\quad 41$ a 50 anos 51 a 60 anos $\quad 60$ anos

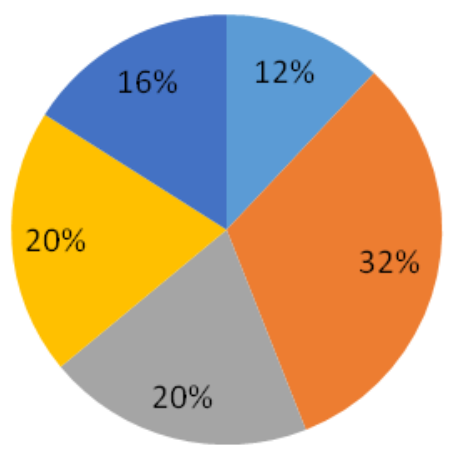

Fonte: Dados da pesquisa. 
Em relação à faixa etária dos peritos, existe uma variação. Os profissionais que têm entre 31 e 40 anos representam 32\% da amostra. A faixa que vai dos 51 aos 60 anos e dos 41 aos 50 anos representa $20 \%$. Dos 21 aos 30 anos, 12\%, e acima dos 60 anos, 16\%.

Questionou-se também o grau de instrução dos entrevistados, conforme o que está disposto no Gráfico 3:

\section{Gráfico 3 - Grau de instrução dos entrevistados}

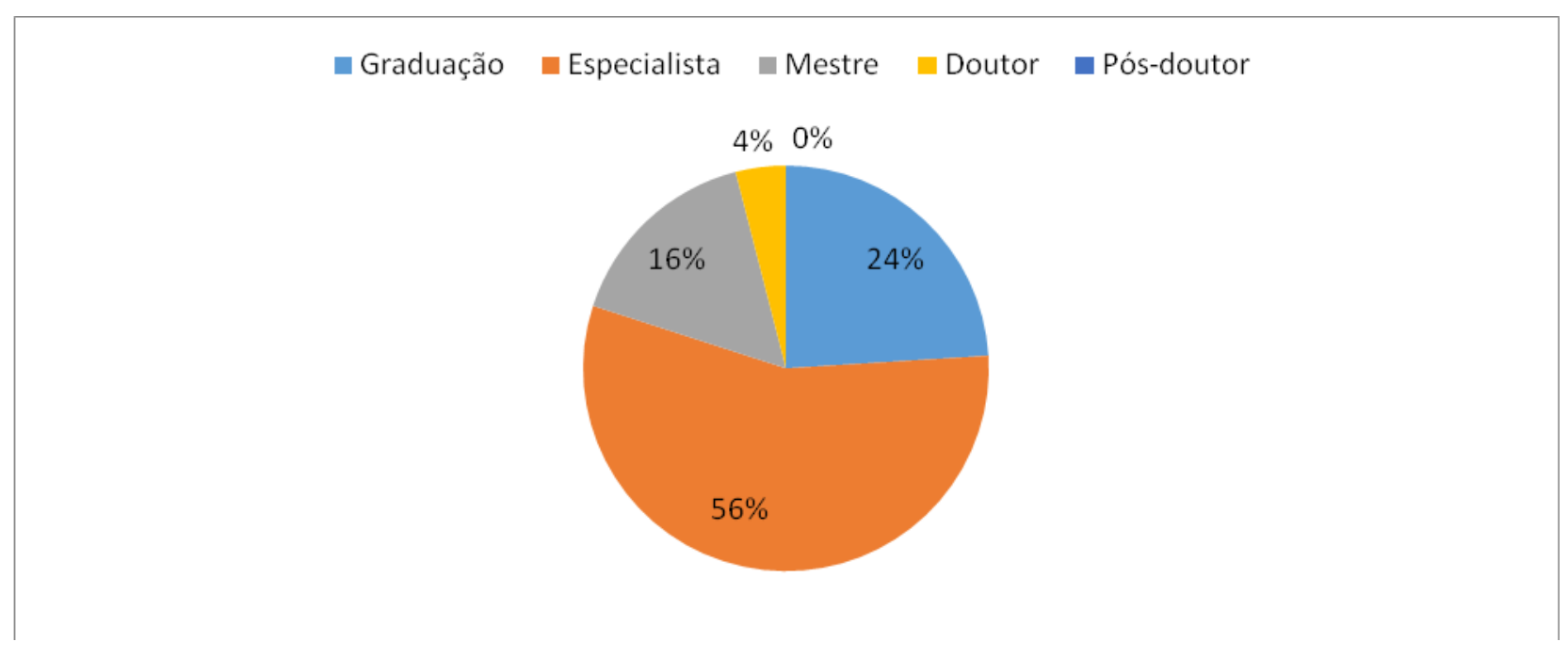

Fonte: Dados da pesquisa.

No que se refere ao grau de instrução, 56\% dos pesquisados são especialistas. Os que têm graduação e mestrado representam $24 \%$ e $16 \%$ da amostra, respectivamente. Apenas um perito possui doutorado, representando $4 \%$ da pesquisa. O resultado distancia-se de estudos anteriores, conforme visto no referencial teórico, em que a maioria dos entrevistados possuía apenas a graduação.

Ao questionar os entrevistados sobre o tempo de atuação na perícia contábil, encontram-se os seguintes resultados: 
Gráfico 4 - Tempo de atuação na perícia contábil

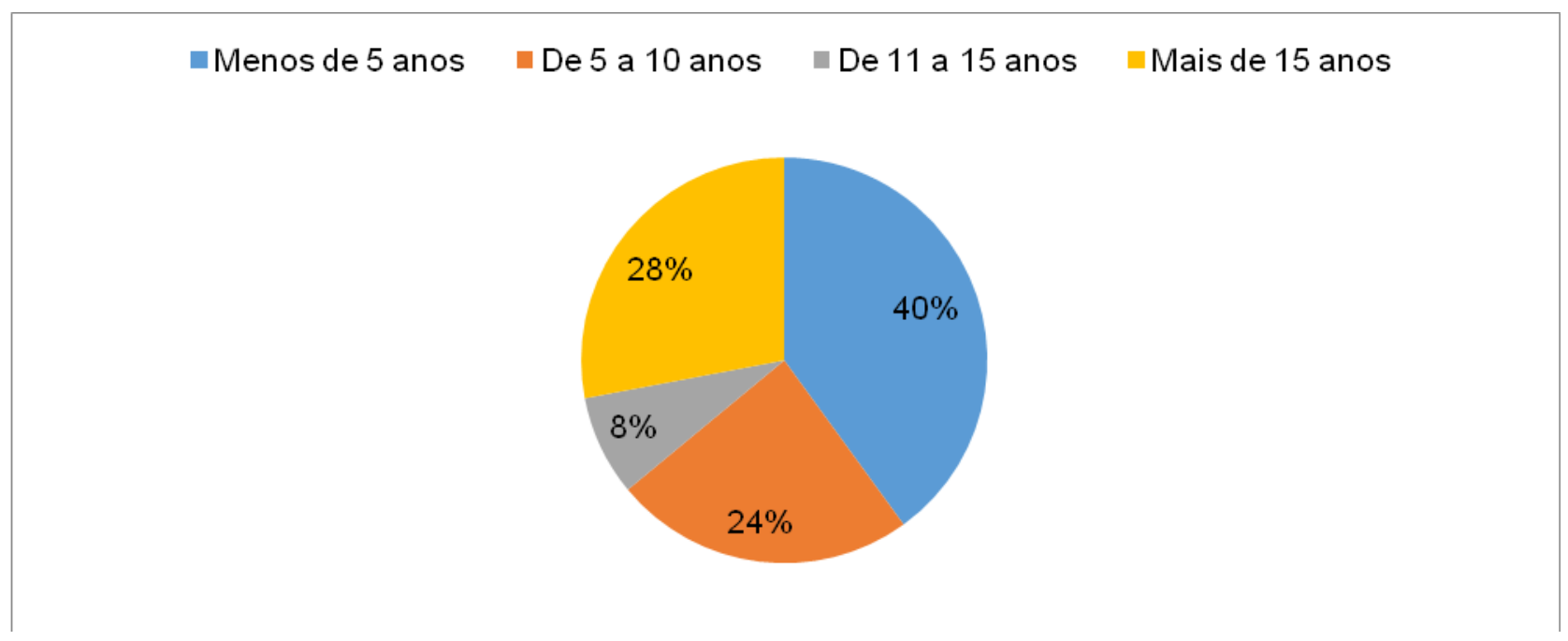

Fonte: Dados da pesquisa.

Conforme o Gráfico 4, a maioria dos peritos (40\%) tem menos de cinco anos de experiência; os que têm mais de quinze anos representam $28 \%$; entre cinco e dez anos, $24 \%$; somente dois dos profissionais $(8 \%)$ possuem entre onze e quinze anos de atividade na área.

O questionário versou sobre a atuação mais frequente entre os peritos. Os dados estão sintetizados no Gráfico 5:

Gráfico 5-Atuação mais frequente

$\square$ Perito contador $\quad$ Perito contador assistente $\quad$ Ambos

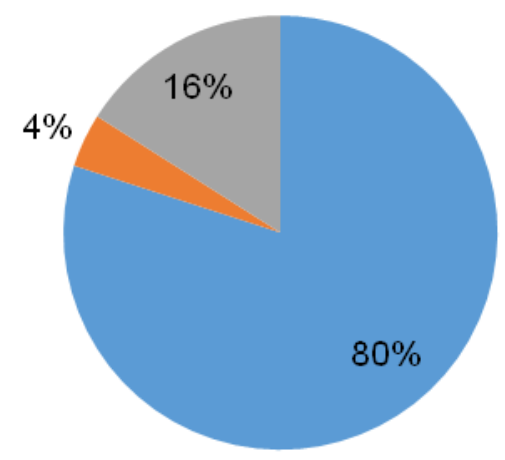

Fonte: Dados da pesquisa. 
Conforme o Gráfico 5, 80\% dos peritos atuam como perito contador, 4\% como perito contador assistente, e 16\% em ambas as funções.

Sobre a participação dos profissionais em cursos de educação continuada, capacitações e qualificações oferecidas inclusive pelo Conselho Federal de Contabilidade (CFC), os resultados são:

\section{Gráfico 6 - Cursos de educação continuada}

\section{Nunca participei $\quad$ Até 2 vezes a cada 6 meses \\ De 3 até 5 vezes a cada 6 meses Acima de 6 vezes a cada 6 meses}

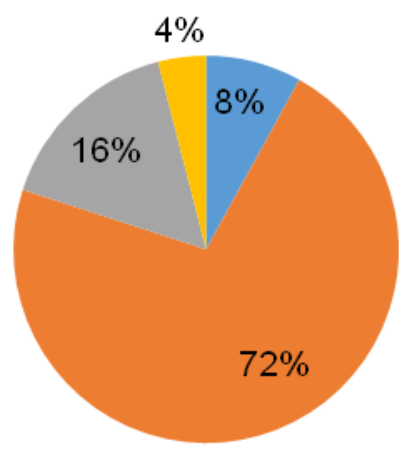

Fonte: Dados da pesquisa.

No que se refere à participação em cursos de educação continuada, 72\% dos questionados afirmam que participam até duas vezes a cada seis meses. Uma amostra bem pequena (8\%) respondeu que nunca participou de cursos. No entanto, a maioria demonstrou interesse em se especializar para adquirir mais conhecimento e, consequentemente, prestar um serviço de melhor qualidade.

Questionou-se aos entrevistados qual a área com maior remuneração. O resultado consta no Gráfico 7: 
Gráfico 7 - Área de maior remuneração

$\square$ Área judicial civil $\square$ Área trabalhista $\square$ Área Tributária $₫$ Área federal $\square$ Não soube responder

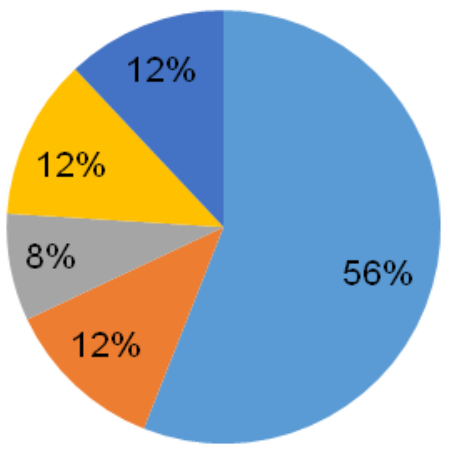

Fonte: Dados da pesquisa.

Segundo os peritos, a área judicial civil é a que proporciona maior remuneração, $56 \%$, seguida das áreas federal e trabalhista, com $12 \%$ cada. Com $8 \%$, a área tributária é a que tem a menor remuneração.

Questionou-se também sobre o valor do rendimento anual previsto para o perito contábil. O Gráfico 8 aponta os resultados:

\section{Gráfico 8 - Rendimentos anuais}

Menos de R $\$ 15.000$

Entre $\mathrm{R} \$ 15.000$ a $\mathrm{R} \$ 20.000,00$

Entre $\mathrm{R} \$ 21.000$ a $\mathrm{R} \$ 30.000,00$ = Entre $\mathrm{R} \$ 31.000$ a $\mathrm{R} \$ 40.000,00$

- Entre $R \$ 41.000$ a $R \$ 50.000,00$ A Acima de $R \$ 50.000,00$

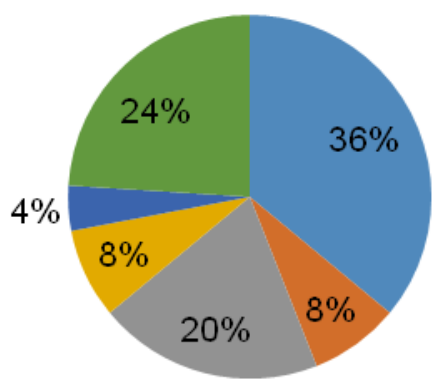

Fonte: Dados da pesquisa. 
De acordo com o Gráfico, 8,36\% dos peritos recebem menos de $\mathrm{R} \$ 15.000,00$ por ano com a realização de perícias; outros $24 \%$ obtêm acima de $\mathrm{R} \$ 50.000,00$ e 20\% recebem entre $\mathrm{R} \$ 21.000,00$ e $\mathrm{R} \$ 30.000,00$. Questionou-se também aos peritos quem normalmente é o responsável por determinar seus honorários. A maioria, $72 \%$, revelou que são os juízes e $28 \%$ afirmaram que é o perito contador. Um dos entrevistados relatou que os peritos apresentam a tabela de honorários de acordo com o trabalho desenvolvido, porém é o juiz quem determina o valor a ser pago.

Questionou-se aos peritos qual a área judicial em que eles atuam com maior frequência. Os dados são apresentados no Gráfico 9:

\section{Gráfico 9- Área judicial de maior atuação}

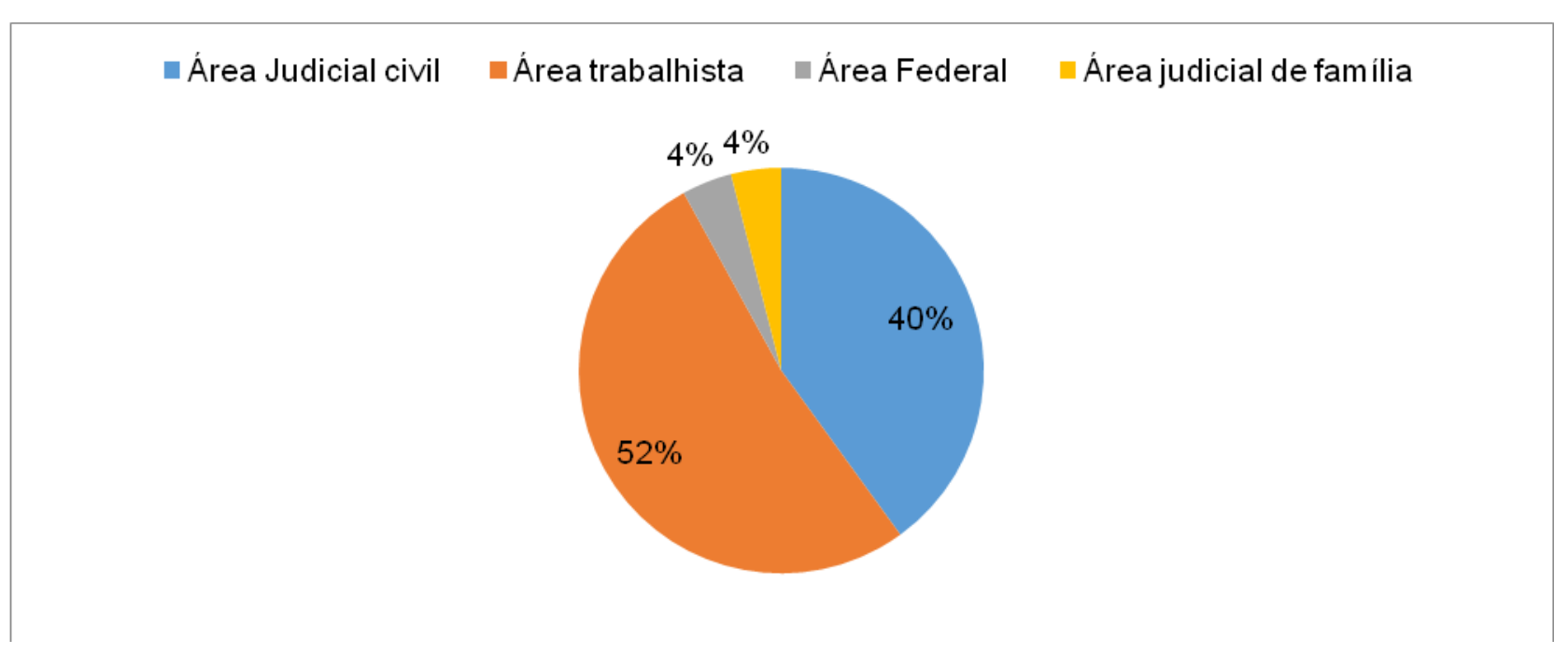

Fonte: Dados da pesquisa.

Com base nas informações, constatou-se que o perito contador atua com mais frequência na área trabalhista, com 52\%. Em segundo lugar aparece a área civil, com $40 \%$.

Com relação à quantidade de perícias anuais realizadas pelos peritos, os dados são: 
Gráfico 10 - Quantidade de perícias anuais

\section{- Entre 1 a 10 processos Entre 11 a 20 processos \\ - Entre 21 a 40 processos $=$ Mais de 40 processos}

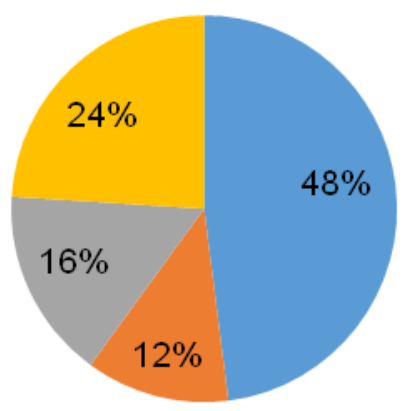

Fonte: Dados da pesquisa.

Conforme mostra o Gráfico 10, a quantidade de perícias anuais realizadas pelos profissionais em análise distribui-se da seguinte forma: entre um e dez processos por ano, 48\%; mais de 40 processos, 24\%; de 21 a 40 processos anuais, $16 \%$; de 11 a 20 processos, $12 \%$.

O Gráfico 11 apresenta os resultados encontrados no tocante ao nível de satisfação com a atividade:

\section{Gráfico 11 - Nível de satisfação com a profissão e a remuneração}

घatisfeito $\square$ Muito satisfeito $\square$ Nem satisfeito, nem insatisfeito $\square$ Insatisfeito $\square$ Muito insatisfeito

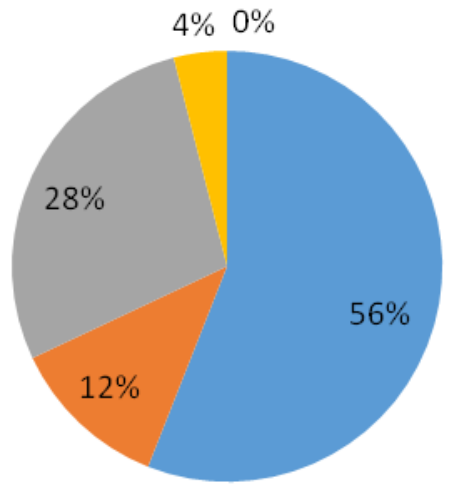

Fonte: Dados da pesquisa.

A maior parte dos peritos contadores judiciais declara que está satisfeita com a profissão, ou seja, $56 \%$ da população estudada; os que admitem que não estão nem satisfeitos nem insatisfeitos somam $28 \%$; os que se dizem muito satisfeitos totalizam $12 \%$ e $4 \%$ se mostram insatisfeitos. 
Questionou-se também se houve maior demanda de perícias contábeis após a inserção no Cadastro Nacional de Peritos Contadores (CNPC). Vale salientar que o CNPC foi criado para centralizar e apresentar à sociedade uma lista de peritos contadores em diversas áreas. O Gráfico 12 traz essas informações:

Gráfico 12 - Cadastro Nacional de Peritos Contadores

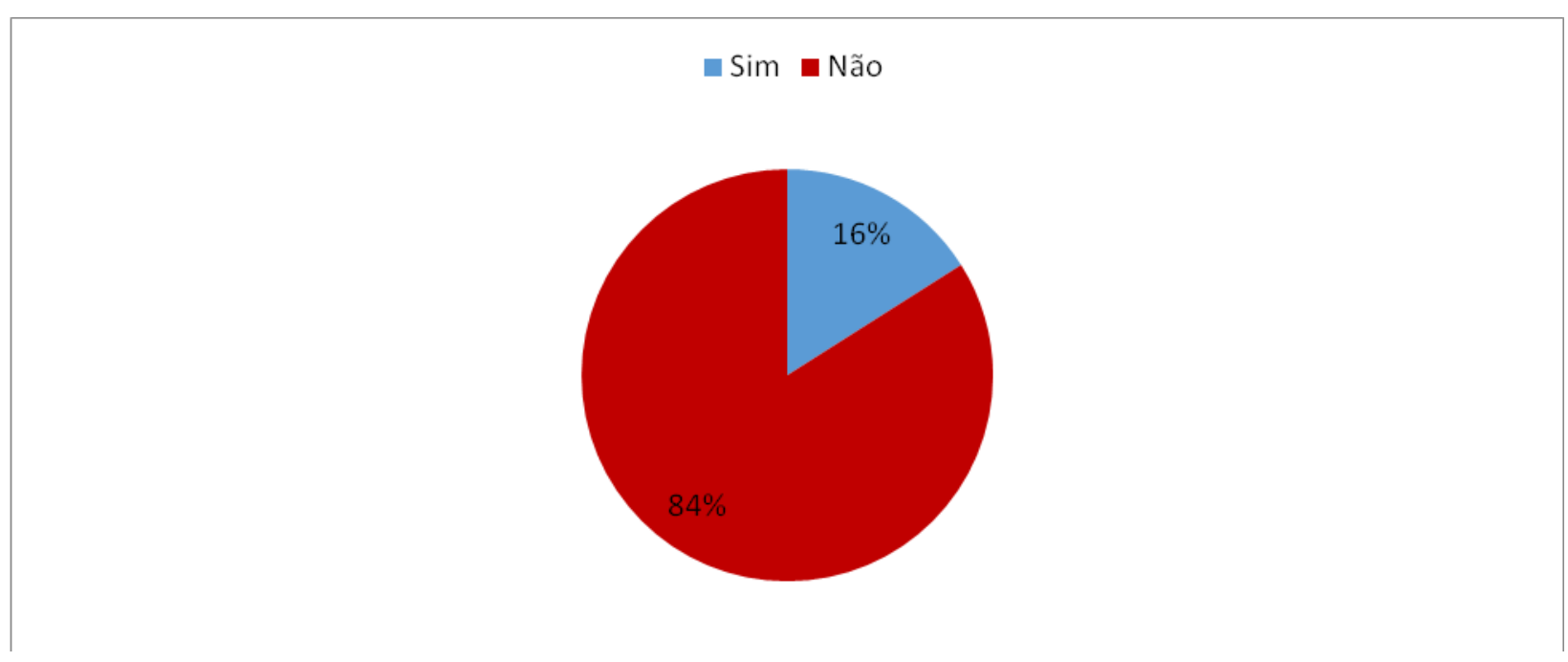

Fonte: Dados da pesquisa.

Segundo os dados analisados, $84 \%$ responderam que a demanda por perícias contábeis não aumentou após sua inserção no CNPC e que possivelmente isso se deve ao fato de não ser obrigatório o juiz nomear somente os inscritos no site. Outros 16\% confirmam que essa ferramenta alavancou os trabalhos.

Os profissionais da área de perícia contábil enfrentam dificuldades no exercício da profissão. O Quadro 2 expõe essas dificuldades e o número de entrevistados que apontaram tais obstáculos: 
Quadro 2 - Dificuldades encontradas no decorrer da profissão

\begin{tabular}{|l|l|l|}
\hline Dificuldades encontradas na Profissão & Total & Porcentagem \\
\hline Classe profissional desunida & 0 & $0 \%$ \\
\hline Obtenção de documentos necessários & 6 & $24 \%$ \\
\hline Apoio das partes envolvidas & 3 & $12 \%$ \\
\hline Tempo para realização da perícia & 4 & $16 \%$ \\
\hline Nomeação por partes dos juízes & 4 & $16 \%$ \\
\hline Concorrência desleal & 0 & $0 \%$ \\
\hline Baixa remuneração & 5 & $20 \%$ \\
\hline Não obtive até a presente data & 1 & $4 \%$ \\
\hline Demora no andamento processual & 1 & $4 \%$ \\
\hline Todas as alternativas & 1 & $4 \%$ \\
\hline
\end{tabular}

Fonte: Dados da pesquisa.

A maior dificuldade dos peritos está na obtenção de documentos necessários para a realização do processo, 24\%; a baixa remuneração representa 20\%; o tempo para a realização da perícia e a nomeação por partes dos juízes, $16 \%$ cada; apoio das partes envolvidas, $12 \%$ e a demora no andamento processual, $4 \%$.

O resultado é diferente dos explanados no referencial teórico. Em uma das pesquisas, a principal dificuldade é a fixação de honorário. Outro autor apontou, com base no seu estudo, a nomeação por parte dos juízes.

Questionou-se também sobre os fatores que concorrem para a inserção no mercado de trabalho. Os dados estão dispostos no Quadro 3: 
Quadro 3 - Inserção no mercado de trabalho

\begin{tabular}{|l|l|l|}
\hline Inserção no mercado de trabalho & Total & Porcentagem \\
\hline Distribuição de currículos & 11 & $44 \%$ \\
\hline Trabalhou com outros peritos contábeis & 4 & $16 \%$ \\
\hline Participação em entidades de classe & 0 & $0 \%$ \\
\hline Buscou especialização/qualificação & 4 & $16 \%$ \\
\hline Conhecimento nas varas trabalhistas & 1 & $4 \%$ \\
\hline Indicação de magistrados & 1 & $4 \%$ \\
\hline Referenciado pelo mercado para alguns juízes & 1 & $4 \%$ \\
\hline Indicação de escritórios de advocacia & 1 & $4 \%$ \\
\hline Todos os itens & 1 & $4 \%$ \\
\hline Não soube responder & 1 & $4 \%$ \\
\hline
\end{tabular}

Fonte: Dados da pesquisa.

Quanto aos fatores responsáveis pela inserção no mercado de trabalho, o currículo é o método mais utilizado pelos profissionais, com 44\%; aqueles que buscam especialização/qualificação e já trabalharam com outros peritos contábeis somam $16 \%$.

\section{Considerações finais}

Acredita-se que esta pesquisa foi relevante para a classe de peritos contadores. O objetivo geral foi caracterizar o perfil dos peritos contadores judiciais do estado de Pernambuco registrados no CNPC. Verificou-se que a maioria dos profissionais é composta por homens na faixa etária de 31 a 41 anos, especialistas, com menos de cinco anos de atuação.

Constatou-se que as principais dificuldades dos peritos para se inserirem no mercado de trabalho são, pela ordem: obtenção de documentos necessários ao processo; baixa remuneração; tempo para realização da perícia; nomeação por partes dos juízes e apoio das partes envolvidas. 
Conforme mostra a análise, $80 \%$ dos entrevistados exercem suas atividades como perito contador. A área trabalhista foi a que apresentou maior demanda, no entanto, a área civil é a que proporciona uma remuneração maior. Os profissionais executam entre um e dez processos por ano e possuem uma renda anual de menos de $\mathrm{R} \$ 15.000,00$.

Os peritos afirmaram, ainda, que estão satisfeitos com a profissão e que continuam sempre procurando uma forma de se inserir no mercado de trabalho, seja por meio de currículos, do trabalho com outros contadores ou da especialização/qualificação. Alguns declararam que participam de cursos de educação continuada até duas vezes em um período de seis meses.

É pertinente frisar que $84 \%$ dos questionados alegaram que a inscrição no CNPC não aumentou a demanda por perícias contábeis. A proposta é que a nomeação por parte dos juízes se consolide mediante norma que sancione consultar a lista de peritos inscritos no CNPC para assumir um processo judicial. Ademais, que os profissionais passem por um exame classificatório que comprove suas habilidades para exercer as funções que lhes são atribuídas.

Vale ressaltar que, para se inscrever no Cadastro Nacional de Peritos Contadores (CNPC), o egresso do curso de Ciências Contábeis deve submeter-se à prova elaborada pelo Conselho Federal de Contabilidade ção e ser aprovado.

Como sugestão para futuros trabalhos de pesquisa, propõe-se replicar este estudo e fazer uma comparação do perfil profissional dos peritos contadores judiciais nos estados da região Nordeste.

\section{Referências}

ANDRADE, M. D.; TRAVASSOS, S.K.M. Perícia Contábil: uma abordagem influencialdo laudo na decisão judicial. Revista Tema, v.8, n.12, 2009.

ARAUJO, F.J.; LIMA, J.S. O mercado de trabalho da perícia contábil. In: $18^{\circ}$ Congresso Brasileiro de Contabilidade. Anais... Gramado/RS, 2008.

AQUINO, A. A.; IMONIANA, J. O. Contabilidade Forense e Perícia Contábil: um estudo fenomenográfico. Revista Organizações em contexto, v.13, n.26, jul.-dez.2017.

BIZZOTO, B.L.S.; DA MOTTA, M.E.V; RAMONI, F.M.Z. O perfil profissional dos peritos contadores de Curitiba-PR. In: XV Mostra de iniciação científica, pós-graduação, Anais...Caxias do Sul/RS, 2015. 
CARÍSsimO, C. R.; MOREIRA, M. A.; OrNELAS, M. M. G.; SILVA, J. T. M. Uso da Análise Hierárquica (AHP) para Identificação da Preferência de PeritosContadores Quanto ao Método de Avaliação de Sociedades em Perícias Contábeis. Revista de Educação e Pesquisa em Contabilidade, v. 10, n. 1, p. 46-64, 2016.

CERVO, Amado Luiz; BERVIAN, Pedro Alcino. Metodologia científica. 5. ed. São Paulo: Makron Books, 2002.

CFC - CONSELHO FEDERAL DE CONTABILIDADE. Dá nova redaçãoà NBC T 13 - Perícia Contábil.

CFC - CONSELHO FEDERAL DE CONTABILIDADE. Aprova a NBC PG 100 - Aplicação Geral aos Profissionais da Contabilidade.

CFC - CONSELHO FEDERAL DE CONTABILIDADE. Dá nova redação à NBC PP 01 - Perito Contábil.

CPC - CÓDIGO DE PROCESSO CIVIL, Lei n n 13.105/2015. Disponível em:< http://www.planalto.gov.br/ccivil_03/_Ato2015-2018/2015/Lei/L13105.htm>. Acesso em: 5 dez. 2018.

ESPIRITO SANTO, T. M. C. Avaliação do perfil profissional do perito contábil descrito na NBC PP 01 sob a ótica da gestão de competências: um estudo com discentes, profissionais e usuários dos serviços de perícia contábil. Monografia. Universidade Federal do Rio Grande do Norte: Natal, 2013.

FELDMANN, M.; GAUER, M. Estudo sobre o perfil de peritos contadores no Rio Grande do Sul. Revista Novos Horizontes, v.6, n.1, 2010.

GONÇALVES, P.C.; MACHADO, M. R.; MACHADO, L. S.; ZANOLLA, E. Características do peritocontador: perspectiva segundo juízes da Justiça Federal, advogados da União e peritos-contadores no contexto goiano. Revista Contemporânea de contabilidade, v.11. n.22, p.119-140,jan./abr.2014.

SALLES, G. L; MACHADO, M. R. R.; ZANOLLA, E; MACHADO, L. S.PERÍCIA CONTÁBIL: Análise bibliométricaemperiódicos brasileiros, Sociedade, Contabilidade eGestão, Rio de Janeiro, v. 11,n. 1, jan/abr 2016. 
MATIAS, M. A; SILVA, G. Perícia Contábil: a visão dos contadores mineiros sobre os requisitos necessários, as atribuições e o campo de atuação da área. Revista Mineira de Contabilidade, v. 2, n. 42, p. 28-35, 2011.

Ministério do Trabalho que define na Classificação Brasileira de Ocupações - CBO. Disponível em: <http://www.mtecbo.gov.br/cbosite/pages/pesquisas/BuscaPorCodigo.jsf >. Acesso em 03 dez. de 2018.

MONTANDON, M. M.; SIQUEIRA, J. R. M.; OHAYON, P. Avaliação de empresas em Perícias Contábeis: um estudo de casos. Pensar Contábil, v. 10, n. 39, art. 2, p. 1-15, 2008.

MURRO, Eduardo Vinícius Bassi; BEUREN, Ilse Maria. Redes de atores na perícia contábil judicial: uma análise à luz da Teoria Ator-Rede. Rev. bras. gest. neg., São Paulo , v. 18, n. 62, p. 633-657, dez. 2016 - Disponível em $\quad<$ http://www.scielo.br/scielo.php?script=sci_arttext\&pid=S180648922016000400633\&lng=pt\&nrm=iso $>. \quad$ acessos em $15 \quad$ jan. 2020. http://dx.doi.org/10.7819/rbgn.v18i62.2743.

NEVES JUNIOR, Idalberto Jose das et al . Perícia Contábil: estudo da percepção de juízes de Primeira Instância na Justiça do Trabalho sobre a qualidade e a relevância do trabalho do perito. Rev. bras. gest. neg., São Paulo , v. 15, n. 47, p. 300-320, jun. 2013 . Disponível em $<$ http:/ /www.scielo.br/scielo.php?script=sci_arttext\&pid=S180648922013000200300\&lng=pt\&nrm=iso $>$ acessos $\quad$ em $\quad 15 \quad$ jan. 2020. http://dx.doi.org/10.7819/rbgn.v15i47.1254.

SANTOS, V. D.; CUNHA, P. R.; TANQUELLA, M.; VALENTIM, I. Ruídos no processo de comunicação de perícias contábeis: um estudo na região do Alto Vale do Itajaí - SC. Sociedade, Contabilidade e Gestão, v. 8, n. 3, p. 55-72, 2013. 